\title{
Omurga kırıklı hastayı değerlendirme
}

\author{
Evaluation of the patient with spine fracture
}

\author{
İsmail Safa Satoğlu, Ömer Akçalı
}

Dokuz Eylül Üniversite Hastanesi, Ortopedi ve Travmatoloji Anabilim Dalı, İzmir

Torakolomber omurga kırıkları genellikle yüksek enerjili travmalarla oluşur. Bu nedenle, ilk önce hava yolu, solunum ve dolaşımın devamlılığı kontrol edilmelidir. Sıklıkla; hemotoraks, pnömotoraks, ürogenital yaralanmalar ve batın solid organ yaralanmaları gibi sistem yaralanmaları eşlik edebilir. Klinik değerlendirmede sistem muayenesinden sonra nörolojik değerlendirme önemlidir. Duyu, motor ve refleks muayeneleri yapılmalıdır. Nörolojik tablonun değerlendirilmesi ve kayda alınmasında ASIA (American Spinal Injury Association) skorlama sistemi ve Frankel değerlendirmesi kullanılabilir. Total parapleji saptanan hastalarda erken dönemde bulbokavernöz refleks alınmaması hastanın spinal şokta olduğunu gösterir. Total nörolojik kayıplarda prognoz kötü iken parsiyel kayıplarda zamanla düzelmeler görülebilir.

Anahtar sözcükler: omurga kırıkları; nörolojik bakı; Frankel skoru; ASIA skoru
Thoracolumbar spine fractures generally occur due to high energy traumas. Therefore, first of all, airway, breathing, and circulation must be checked. Haemothorax, pneumothorax, urogenital injuries, and solid abdominal organ injuries may accompany the spine fractures frequently. Neurologic evaluation is very important after systemic examinations. Sensation, motor movements, and reflexes should be checked. ASIA scoring and Frankel grading systems may be used for neurologic evaluation and registration. Bulbocavernous reflex negativity in the patients with total neurologic loss in early post-traumatic period may indicate the spinal shock. The prognosis is very poor in total paraplegics but some neurologic impairment may be seen in the patients with incomplete neurologic deficit.

Key words: spine fractures; neurologic examination; Frankel grade, ASIA score

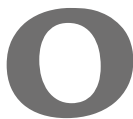

murga kırıkları, düşük enerji ile oluşan basit osteoporotik çökme kırıkları şeklinde de olabilir ama çoğunluğu trafik kazaları veya yüksekten düşmelerle meydana gelen yüksek enerjili travmaların yol açtığı ve nörolojik kayıpların görülebildiği önemli yaralanmalardır. Torasik ve lomber omurga kırıklarının yaklaşı \%90'ı biyomekanik özellikleri nedeniyle torakolomber bileşkede meydana gelir ve bu kırıkların \%10-20'si burst kırıkları olarak karşımıza çıkar. ${ }^{[1]}$ Burst (patlama) kırıklarının spinal kanalı \%50'den fazla daralttığı olguların yaklaşık \%50'sinde nörolojik kayıplar oluşabilmekte ve özellikle genç popülasyonda işgücü kaybı ve morbiditelere yol açmaktadır. ${ }^{[2]}$

Omurga kırıklarına eşlik eden omurilik yaralanmalarının \%3-25'inin, travmanın olduğu erken dönemde hastanın tedavi olacağı merkeze ulaşana veya tedavinin başlatılacağı zamana kadar geçen sürede meydana geldiği gösterilmiştir. ${ }^{[3]}$ Bu nedenle, ileri Travma Yaşam
Desteği (ITYD - Advanced Trauma Life Support protocol) kılavuzunda, travma geçirmiş ve omurga kırığı şüphesi bulunan hastaların boyunluklar ve yapıştırıcı bantlar yardımı ile başlarının sabitlenmesi, hastaneye nakli ve gerekli filmlerin çekilmesi esnasında travma tahtaları ile nakledilmesinin önemi belirtilmektedir. ${ }^{[4]}$ Konumuz torakal ve lomber omurga yaralanmaları olduğu için, bu yazımızda servikal sorunlarla ilgili daha fazla ayrıntıya girilmeyecektir.

Yüksek enerji sonucu meydana gelmiş bir omurga yaralanmalı hastanın hastaneye ulaştırılması ve acil servise giriş yapılması sonrasında yapılacak işlemler, ITYD'nin A-B-C'si olarak bilinen işlemlerdir. Bunlar sırasıyla; A havayolunun (airway) açık olmasının sağlanması, B (breathing) solunumun değerlendirilmesi, $C$ (circulation) dolaşımın damar yolu ile desteklenmesi, D (disability) kısa bir nörolojik değerlendirme ile muhtemel hasarın ön değerlendirilmesi ve $\mathrm{E}$ (exposure)

- İletişim adresi: Prof. Dr. Ömer Akçalı, Dokuz Eylül Üniversite Hastanesi, Ortopedi ve Travmatoloji Anabilim Dalı, Balçova, İzmir Tel: 0533 - 7157086 e-posta: omer.akcali@deu.edu.tr, omerakcali@gmail.com

- Geliș tarihi: 1 Kasım 2018 Kabul tarihi: 1 Kasım 2018 
giysilerin çıkarılması ve kütük çevirme yöntemi ile bedendeki ekimoz, açık yara, deformite, krepitasyon vb. bulguların tespit edilmesidir. Bu esnada, ana probleme eşlik etmekte olan ek yaralanmaların gözden kaçııılmaması önemlidir. Torakal ve lomber kırıklarda, servikal kırıklara oranla, ani solunum durmaları çok sık görülmesi beklenen bir komplikasyon olmasa bile, özellikle torakal omurga kırıklarına sıklıkla eşlik eden toraks yaralanmalarının pnömotoraks, hemotoraks, kot kırıkları ve diyafram yırtılmalarına yol açarak solunumu olumsuz etkileyebileceği akıldan çıkarılmamalıdır.

Havayolu ve solunumun temininden sonra en önemli aşama hastanın hemodinamisinin sağlanmasıdır; çünkü eşlik edebilecek batın içi yaralanma veya pelvis kırıklarının yol açabileceği kanamalar sıklıkla hipovolemik şoka yol açabilir. Hipovolemik şoktaki hastalar hipotansif ve taşikardiktir. Bu hastaların ekstremiteleri de soğuktur. Nörojenik şok ise spinal kord yaralanmalı bir hastada sempatik tonus kaybının yol açtığı hipotansiyon ve "bradikardi" durumu olarak tanımlanır; bu hastalarda ekstremiteler sıcaktır. ${ }^{[5]}$ Servikal kırıklara oranla torakal omurga kırıklarında nörojenik şokun daha az görüldüğü ve T6 omur seviyesinin distalinde ise hemen hemen görülmediği akılda tutulmalıdır. ${ }^{[6]}$ Hipovolemik şoktaki hastalara damar yolundan hızlıca sıvı ve kan ürünleri takviyesi yapılarak tansiyon yükseltilmelidir. Nörojenik şoktaki hastalara ise sıvı desteği ile beraber dobutamin veya dopamin gibi kronotropik ajanlar verilmelidir. ${ }^{[5]}$ Spinal kord yaralanmalı hastalarda omuriliğin perfüzyonunun sağlanabilmesi için, travmayı takip eden preop, perop ve postop dönemde ortalama arter basıncının $85 \mathrm{mmHg}$ üzerinde tutulması önemlidir.

Hastanın hemodinamik stabilizasyonunu takiben, travmanın oluş şekli dâhil öğrenilebilecek tüm ayrıntılar sorgulanmalıdır; çünkü yüksek enerji sonucu oluşan omurga kırıklarına yaklaşık \%50 oranında eşlik eden ek yaralanmaların olduğu gösterilmiştir. ${ }^{[7]}$ Travmaların oluş şekillerinin bilinmesi, özellikle eşlik eden bazı patolojilerin atlanmaması konusunda bizlere büyük katkılar sağlar. Buna en güzel örnekler; yüksekten düşme ile gelip kalkaneus kırığı saptanan hastalarda sıklıkla omurga kırıklarının görülmesi, emniyet kemerinin kullanıldığı araç içi trafik kazalarında Chance kırıklarına batın içi organ yaralanmalarının eşlik etmesi gösterilebilir. Bu nedenle, hastanın muayenesi baştan başlayıp ayaklarının parmak ucuna kadar tüm ekstremitelerin muayenesini, batın ve ürogenital muayeneyi ve nörolojik muayeneyi eksiksiz olarak içermelidir. Nörolojik kayıp gelişmiş olan hastalarda nörolojik muayenenin özenle yapılması ve tüm bulguların not edilmesi önemlidir; çünkü nörolojik hasarın hastane şartlarında, tetkikler esnasında, serviste yatarken ve hatta ameliyatın başlamasına kadar ilerleyebileceği ve nörolojik tablonun değişebileceği akıldan çıkarılmamalıdır. Motor ve duyu muayenesinde 'American Spinal Injury Association' tarafından tanımlanan değerlendirme sistemi (ASIA) en çok kullanılan sistemdir. ${ }^{[8]} \mathrm{Bu}$ değerlendirme sisteminde hastanın duyu ve motor seviyelerinin dermatomlar ve miyotomlar aracılığı ile belirlenmesi ve kas güçleri ile derin tendon reflekslerinin değerlendirilmesi esastır. Duyu değerlendirmesinde tüm dermatomlarda iğne ve pamuk ile keskin ve hafif dokunma duyusunun değerlendirilmesi ve 0-1-2-değerlendirilemedi (sırasıyla; cevap yok-zayıf-normal-değerlendirilemedi) şeklinde skorlanması önemlidir. Hangi dermatomlarda hissin hiç olmadığı hangilerinde zayıf olduğu not edilmelidir. Bu aşamada T4'ün meme başları, T10'un umblikus ve L1'in inguinal bağ hizasında olduğu kolayca akılda kalıcı olması bakımından hatırlanabilir. Motor fonksiyon hasarının miyotomlara bağlı olarak değerlendirilmesi ise lomber sinir köklerinin innerve ettiği kaslara göre yapılır. Kuadrisepsin femoral sinirden (L2-3-4), adduktor adale grubunun obturator sinirden (L2-3-4), tibialis anteriorun derin peroneal sinirden (L4), ekstansör hallusis longusun derin peroneal sinirden (L5) ve plantar fleksorların süperfisyel peroneal sinirden (S1) innerve olduğu akılda tutulmalıdır. Derin tendon refleksleri alt motor nöron refleksleridir, patellar tendon L4, tibialis posterior L5, Aşil refleksi S1 fonksiyonlarının değerlendirilmesinde yardımcıdır. Bulbokavernöz refleks ise S2-4 köklerini değerlendiren lokal refleks arkıdır. Perianal duyunun varlı̆̆ ise S4-5 seviyelerinin korunduğunu gösterir.

Acil servis değerlendirmesinde alt ekstremitelerin tam motor kaybı ile birlikte bulbokavernöz refleksin alınamaması hastanın spinal şok evresinde olduğunu gösterir ve teknik olarak bulbokavernöz refleks geri dönene kadar spinal hasarın sınıflandırılamayacağı anlamına gelir. Bulbokavernöz refleksin dönmesi sonrasında motor fonksiyonların komplet mi yoksa inkomplet mi olduğunun değerlendirmesi yapılabilir ve bu aşamadan sonra total motor fonksiyon kaybının varlığı kötü prognoza işaret eder. Burada şu nokta özellikle akılda tutulmalıdır: Spinal şoktan bahsedebilmemiz için spinal kordun hasar görmüş olması, dolayısı ile hastada torakal seviyeli bir kırıkla karşı karşıya olmamız beklenir. Yani L1 seviyesinin altında konus medullaris ve kauda ekina lifleri başlayacağı için, bu seviyenin altında teorik olarak spinal şoktan bahsetmemiz mümkün değildir. L1 seviyesindeki bir kırıkta konus medullaris sendromu (ki birinci motor nöron hasarıdır), L1-L2 seviyesinde ise kauda ekina sendromu (ki ikinci motor nöron hasarıdır), L2 distalindeki bir yaralanmada ise periferik sinir hasarı yani flask paralizi görülmesi beklenebilir. Torakal seviyeli bir kırıkta anal duyunun 
korunmuş olması, mesane fonksiyonlarının korunmuş olabileceği açısından iyi prognoz belirtisi olabilir. Hastada priapizm varlığ ise total spinal kord hasarının göstergesidir; çünkü genital organlarda sempatik tonus kaybının olduğu yerde parasempatik etki devam etmektedir. Yaralanmayı takip eden 72 saat - 1 hafta içerisinde anal duyunun korunuyor olması spinal kord yaralanması sonrasında iyi prognoz işaretidir.

Motor kas güçlerinin değerlendirilmesinde ise kasların gücü 0-5 puan üzerinden değerlendirilir:

0- hareket ve kasılma yok,

1- sadece kasılma var, hareket yok,

2- yerçekimi kaldırıldıktan sonra hareket var,

3- yerçekimine karşı hareket var ancak dirence karşı yok,

4- dirence karşı koyabiliyor ancak yeniliyor,

5- dirence tam karşılık verebiliyor' şeklinde puanlandırılır.

Yukarıda ayrıntıları verilmiş olan nörolojik muayenelerin yapılması sonucunda Frankel skalası kullanılarak hastalar değerlendirilir. ${ }^{[9]}$ Buna göre;

ASIA A (komplet): yaralanma seviyesinin altında S4-5 dahil tam motor ve duyu kaybı,

ASIA B (inkomplet): Duyu korunmuş ancak yaralanma seviyesinin altında S4-5 dahil tam motor kayıp,

ASIA C (inkomplet): Yaralanma seviyesinin altında motor fonksiyon var ancak kas gücü 1-2,

ASIA D (inkomplet): Yaralanma seviyesinin altında motor fonksiyon var ancak kas gücü 3-4,

ASIA E (normal): Normal motor ve duyu fonksiyonu.

Tam kat spinal kord kesisi veya hasarı olan hastalarda prognoz kötü iken, inkomplet yaralanmalarda zaman içerisinde olumlu iyileşmeler görülebilir. Bu nedenle, kaza anından başlayarak hastanın hastaneye nakli, acil serviste ilk müdahalesi ve tedavi yaklaşımında temel prensiplere uyulması önemlidir.
Nörolojik değerlendirmenin devamlı yapılması ve kayıt altına alınması çok önemlidir. Omurga kırıklarının büyük kısmı adli olaylar nedeniyle oluştuğundan, hayatta kalan hastalarda hukuksal süreçler devam edecektir. Bu nedenle, acil servisteki değerlendirmeden itibaren hastanın tedavisi tamamlanıncaya kadar yapılan her nörolojik muayene sonucu ayrıntılı olarak kayıt altına alınmalıdır. Bu kayıtlar ileride, hem hastanın haklarının korunmasında hem de hekimlerin kendilerini olası bir mahkeme sürecinde korumaya almaları açısından çok önemlidir.

\section{KAYNAKLAR}

1. Wood KB, Bohn D, Mehbod A. Anterior versus posterior treatment of stable thoracolumbar burst fractures without neurologic deficit: a prospective, randomized study. J Spinal Disord Tech 2005;18 Suppl 1:S15-23. Crossref

2. Caffaro MF, Avanzi O. Is there a difference between narrowing of the spinal canal and neurological deficits comparing Denis and Magerl classifications? Spinal Cord 2011;49(2):297301. Crossref

3. Theodore N, Hadley MN, Aarabi B, Dhall SS, Gelb DE, Hurlbert RJ, Rozzelle CJ, Ryken TC, Walters BC. Prehospital cervical spinal immobilization after trauma. Neurosurgery 2013; 72 Suppl 2:22-34. Crossref

4. American College of Surgeons. Advanced Trauma Life Support Student Course Manual, 9th ed. Chicago: 2012. pp.174-96.

5. Levi L, Wolf A, Belzberg H. Hemodynamic parameters in patients with acute cervical cord trauma: description, intervention, and prediction of outcome. Neurosurgery 1993;33(6):1007-17. Crossref

6. Vale FL, Burns J, Jackson AB, Hadley MN. Combined medical and surgical treatment after acute spinal cord injury: results of a prospective pilot study to assess the merits of aggressive medical resuscitation and blood pressure management. J Neurosurg 1997;87(2):239-46. Crossref

7. Saboe LA, Reid DC, Davis LA, Warren SA, Grace MG. Spine trauma and associated injuries. J Trauma 1991;31(1):43-8. Crossref

8. Bobby T, Frank J. Eismont. Physical Examination. In: Vaccaro AR. Fractures of the Cervical, Thoracic and Lumbar Spine. New York, Basel: Marcel Dekker, Inc.; 2003. pp.69-80.

9. Maynard FM Jr, Bracken MB, Creasey G, Ditunno JF Jr, Donovan WH, Ducker TB, Garber SL, Marino RJ, Stover SL, Tator CH, Waters RL, Wilberger JE, Young W. International Standards for Neurological and Functional Classification of Spinal Cord Injury. Spinal Cord 1997;35(5):266-74. Crossref 